Journal of Patient-Centered

\title{
Use of Urine Antigen Testing for Blastomyces in an Integrated Health System
}

Dennis J. Baumgardner

Follow this and additional works at: https://aah.org/jpcrr

Part of the Bacteria Commons, Bacterial Infections and Mycoses Commons, Environmental Public Health Commons, Health Services Research Commons, Infectious Disease Commons, and the Other Analytical, Diagnostic and Therapeutic Techniques and Equipment Commons

\section{Recommended Citation}

Baumgardner DJ. Use of urine antigen testing for Blastomyces in an integrated health system. J Patient Cent Res Rev. 2018;5:176-82. doi: 10.17294/2330-0698.1452

Published quarterly by Midwest-based health system Advocate Aurora Health and indexed in PubMed Central, the Journal of Patient-Centered Research and Reviews (JPCRR) is an open access, peer-reviewed medical journal focused on disseminating scholarly works devoted to improving patient-centered care practices, health outcomes, and the patient experience. 


\title{
Use of Urine Antigen Testing for Blastomyces in an Integrated Health System
}

\author{
Dennis J. Baumgardner, MD \\ Aurora UW Medical Group, Aurora Health Care, Milwaukee WI; Department of Family Medicine and Community Health, \\ University of Wisconsin School of Medicine and Public Health, Madison, WI; Center for Urban Population Health, \\ Milwaukee, WI
}

Purpose Blastomycosis, an endemic fungal infection, mimics many other diseases. We explored the use of Blastomyces urine antigen (BuAg), reportedly the most sensitive noninvasive test, in clinical practice and compared it to other noninvasive tests.

Methods A total of 836 BuAg tests performed on unique patients (first test only) at one large integrated health system from June 2013 to May 2016 were retrospectively reviewed to examine test characteristics and demographic features. Of these, 100 cases from 2015, a year containing a large local blastomycosis outbreak, were randomly selected for detailed analysis.

Results Demographics for the BuAg-tested population: mean age 54.9 years, $55.0 \%$ male, $78.9 \%$ white, 213 zip codes represented. Test results were positive in 49 of 836 (5.9\%, across 43 zip codes); 16 of the 49 (32.7\%) stemmed from the 2015 outbreak. BuAg-positive patients were younger than those who tested negative, even with outbreak subjects removed ( 48.1 vs 56.7 years, $\mathrm{P}=0.008$ ); and Asians and males were overrepresented. Sensitivity/specificity/positive predictive value of BuAg test was $87.9 \% / 97.9 \% / 76.3 \%$, respectively, based on 33 culture-positive cases. Only 2 of 20 culture-positive cases were found positive by Blastomyces antibody $(\mathrm{Ab})$ immunodiffusion (ID) test and 0 of the other 18 by Ab complement fixation (CF). Of those with positive BuAg who were co-tested, $16.1 \%$ were positive by Ab ID and $3.9 \%$ by Ab CF. Histoplasma urine antigen was co-performed with BuAg in 578 patients $(69.1 \%)$ and positive in 25 (4.3\%); 16 of these 25 (64.0\%) also were BuAg-positive (ie, known cross-reactivity). Of the 100 patients examined for index illness details, 7 (6 BuAg-positive) were ultimately diagnosed with blastomycosis, 7 other fungal disease, 26 noninfectious lung disease, 22 pneumonia, 5 skin lesions, 6 malignancies, 3 mycobacteria, 11 other, and 1 unknown. Of 100, 12 were tested by BuAg based on symptoms.

Conclusions Blastomyces urine antigen is commonly used for work-up of broad differential diagnoses or known exposures. Not adding Ab ID/CF diagnostic tests ( $\$ 80$ each) to the BuAg test saves money without losing sensitivity. (J Patient Cent Res Rev. 2018;5:176-182.)

Keywords Blastomyces; blastomycosis; antigens, fungal; Histoplasma; disease outbreaks

$\mathrm{B}$ lastomycosis is a potentially serious systemic and cutaneous fungal infection endemic to eastern North America. ${ }^{1-3}$ Disease is acquired from the environment by inhalation of spores of the etiologic fungi Blastomyces dermatitidis

Correspondence: Dennis J. Baumgardner, MD, Aurora Sinai Medical Center, 1020 N. 12th Street, \#4180, Milwaukee, WI 53233 (dennis.baumgardner@aurora.org) or Blastomyces gilchristii. ${ }^{2,4}$ Incidence rates are particularly high in Wisconsin compared to the rest of the nation. ${ }^{2,5}$ Pulmonary disease, the most common clinical manifestation, has a broad differential diagnosis, ${ }^{1,6,7}$ and proper diagnosis is important to avoid increased morbidity and mortality. Dissemination beyond the lung may occur to most any organ or tissue, particularly skin, bone, genitourinary system and central nervous system. ${ }^{1,2,6}$ Thus, the differential diagnoses of various presentations of blastomycosis may be quite broad. ${ }^{1,6}$ 
Fungal culture is reportedly $86 \%$ sensitive in pulmonary cases and may take up to 5 weeks for the organism to grow. ${ }^{8}$ Fungal smears for rapid diagnosis vary from $24 \%$ to $55 \%$ sensitivity depending on the site sampled. ${ }^{3}$ Blastomycosis diagnosis by histopathology, compared with culture, was $85 \%-89 \%$ sensitive in two studies. ${ }^{9} 10$ Modern serologic tests approach $80 \%-90 \%$ sensitivity; however, antibody testing by complement fixation (CF) or immunodiffusion (ID) is insensitive. ${ }^{1,2}$

Urine antigen testing for Blastomyces (BuAg) has been described for the past 14 years, ${ }^{11}$ though it has only been commercially available and more frequently utilized in the past few years. It uses readily available, noninvasive urine samples, and turnaround time is frequently within 48 hours, much sooner than fungal culture. Reported sensitivities range from $76 \%$ to $93 \%,{ }^{11-15}$ with specificities of $77 \%-79 \% .{ }^{11,15}$ Specificity improved to $99 \%$ by using control subjects who were healthy or had nonfungal infections, and by use of urine antigen detection by quantitative enzyme immunoassay. ${ }^{12}$ There is, however, significant crossreaction in patients with histoplasmosis. ${ }^{11,12}$

Increased use of $\mathrm{BuAg}$ may be leading to more blastomycosis diagnoses in community settings. ${ }^{13}$ However, there have been few studies that have examined the epidemiologic and clinical features of patients on whom this test is ordered and test characteristics in a general patient population. ${ }^{13,14}$ This study explored the demographic and clinical features of patients on whom BuAg is performed, as well as test characteristics, in an eastern Wisconsin integrated health system. Understanding of these features may guide clinicians regarding the usefulness of this test in patients who may have blastomycosis and its ability to supplant older serological tests.

\section{METHODS}

\section{Setting and Subject Selection}

Subject identifiers for this retrospective electronic medical records (EMR) review were obtained from the affiliated laboratory of a large, integrated health system that included, at the time of the study, 15 hospitals and 159 outpatient clinics throughout eastern Wisconsin and extreme northeastern Illinois. This area contains the majority of Wisconsin's urban and suburban population. Our system houses medical records of more than 1.2 million unique patients. The geodemographic features of blastomycosis cases in our health system have been previously described. ${ }^{16}$ Approvals for the present study were obtained from the local institutional review board.

Subjects included all inpatients and outpatients, regardless of age, who had $\mathrm{BuAg}$ processed through our laboratory during the time period June 2013 to May 2016. All BuAg tests within the study period were performed at our reference laboratory, which uses quantitative sandwich enzyme immunoassay technology to detect a galactomannan found in the cell wall. ${ }^{12}$ The first BuAg performed during this time period on each unique patient was examined as the "index test." Subsequent BuAg tests also were recorded. Additional blastomycosis case finding (including diagnosis by culture, histopathology, and/ or cytology/smear) over this same time period was obtained from a search of inclusive ICD-9/10 codes by our institution's research analytics department.

These patient lists were used to perform chart review on all subjects for demographic features and to calculate test characteristics of $\mathrm{BuAg}$, including comparison to the other common noninvasive diagnostic tests for Blastomyces, CF and ID. For these comparisons, other tests for Blastomyces were included if they were obtained during work-up of the same inpatient or outpatient illness episode as the BuAg test. For fungal culture or histo/cytopathology, these tests were generally concurrent but always within 33 days (sometimes awaiting bronchoscopic examination). For CF and ID tests, virtually all were obtained within 8 days of $\mathrm{BuAg}$ (a single outlier was within 25 days).

In addition, the records of 100 randomly selected subjects from the laboratory list were further examined for details of the clinical features and related workup of the illness that led to the ordering of BuAg and the ultimate diagnosis of that illness. All 100 of these selected cases were drawn from 2015, a year that included a large mid-year outbreak of blastomycosis associated with the Little Wolf River in Waupaca County, Wisconsin. ${ }^{17}$ This allowed inclusion of outbreak and nonoutbreak-related subjects tested with BuAg (but, of course, only those seen and tested in our health system). 
Inpatient and outpatient records from the index illness were reviewed and included admission history; physical examination, clinic, emergency department, or urgent care notes from the time of initial presentation; discharge summaries; notes from key consultants (eg, infectious disease, pulmonary or critical care medicine); key follow-up visit notes; and laboratory and radiologic reports. Clinical features were recorded if the EMR included documentation of either the presence or absence of the sign or symptom.

\section{Statistical Analysis}

Categorical data were analyzed using Fisher's exact test. Normality testing utilized the Anderson-Darling method. Continuous variables were compared with twosample t-tests of means for distributions approximating normal (age), and Mann-Whitney test for non-normal distributions (BuAg quantitative values). P-values less than 0.05 were considered significant.

\section{RESULTS}

$\mathrm{BuAg}$ was performed on 836 individuals, who represented 213 zip codes; mean age of population was $54.9 \pm 18.0$ (range: $5-95$ ) years, $55.0 \%$ were male, and $78.9 \%$ were white. The last 7 months of 2013 yielded $94 \mathrm{BuAg}$ tests (13.4/month), 261 tests were from 2014 (21.8/month), 356 from 2015 (outbreak year, 29.7/ month), and 125 were from the first 5 months of 2016 (25.0/month).

BuAg was positive in 49 of 836 (5.9\%, representing 42 zip codes). Among positive tests, 16 of 49 (32.7\%) were part of the large 2015 outbreak. Among individuals who were tested and had recorded exposure to the outbreak geography $(\mathrm{n}=49), 16(32.7 \%$, representing 28 zip codes), were positive. BuAg-positive patients were younger than those testing negative (Table 1), even when outbreak subjects were removed (48.1 \pm 17.9 vs $56.7 \pm 17.1$ years, $\mathrm{P}=0.008$ ); males were overrepresented in testing positive. Those of Asian ancestry, both those of Southeast Asia $(\mathrm{P}<0.0001)$ and other parts of Asia ( $\mathrm{P}=0.005)$, were overrepresented compared to whites.

The sensitivity of BuAg was $87.9 \%$, specificity $97.9 \%$, and positive predictive value $76.3 \%$ (based on 33 culture-positive cases). There were 2 additional cases of blastomycosis diagnosed by positive histopathology or cytology/smear, 1 of which was BuAg-positive (sensitivity for all 35 cases: 85.7\%).

\section{BuAg-Positive Population}

Among the 49 BuAg-positive patients, 43 had pulmonary disease (including 4 who additionally had skin disease, 1 each who additionally had bone, prostate, or central nervous system disease, and 2 with widely disseminated involvement); 3 had skin-only disease, and 3 had bone-only disease. The average quantitative titer of all 49 patients was $2.7 \pm 3.5 \mathrm{ng} / \mathrm{ml}$; the median titer was 1.4 (range: $<0.2$ to $>14.7$ ). Median titer did not differ between outbreak and nonoutbreak cases ( 1.2 vs $1.5, \mathrm{P}=0.23$ ), nor between cases with and without apparent pulmonary disease (1.5 vs 1.2 , $\mathrm{P}=0.85$ ) or pulmonary disease only versus disease spread beyond the lungs ( 1.5 vs $1.3, \mathrm{P}=0.50)$.

In the 15 cases $(30.6 \%$ of the total 49$)$ in which $\mathrm{BuAg}$ was the only positive test for Blastomyces (in 3 cases it was the only test performed), only 2 of 15 (13.3\%) subjects had blastomycosis identified beyond the lungs. In cases where culture and/or histopathology and/or cytology/smear also were positive, 13 of 34 (38.2\%) had disease beyond the lungs $(\mathrm{P}=0.10)$.

Only 2 of $19(10.5 \%)$ culture-positive cases were positive by Blastomyces antibody ID test, 0 of 17 by antibody CF. Of those with positive BuAg, 16.1\% of those co-tested were positive by ID, $4.0 \%$ by CF. All 11 positive ID/CF cases were positive by BuAg. In the Little Wolf River outbreak population, $\mathrm{BuAg}$ was the only test performed for Blastomyces detection in 19 of $49(38.8 \%)$ cases. Similar to nonoutbreak cases (31 of 34 [91.2\%]), 14 of 16 (87.5\%) BuAg-positive cases had at least one other test for Blastomyces performed. $\mathrm{BuAg}$ was the only positive test in 9 of $16(56.3 \%)$ outbreak cases versus 6 of $34(17.6 \%, \mathrm{P}=0.009)$ nonoutbreak cases ( 8 of 14 vs 3 of $31, \mathrm{P}=0.001$, if only co-tested cases are considered).

Serial BuAg tests were performed in 17 of 49 (34.7\%) positive index tests. A total of two tests were done in 11 cases, three tests in 4 cases, four tests in 1 case and five tests in 1 case. The median time of first repeat test was 45 days (range: 2-300 days), and 7 of 17 (41.2\%) second tests were negative (range: 30-300 days later). All serial titers were lower than previous tests except 
Table 1. Demographic Features of BuAg-Tested Subjects

\begin{tabular}{|c|c|c|c|c|}
\hline Characteristic & $\begin{array}{c}\text { Total, } \\
\mathrm{N}=836\end{array}$ & $\begin{array}{c}\text { Positive BuAg, } \\
n=49\end{array}$ & $\begin{array}{c}\text { Negative BuAg, } \\
n=787\end{array}$ & $P$ \\
\hline Female & $376(45.0 \%)$ & $15(4.0 \%)$ & 361 (96.0\%) & \\
\hline Male & $460(55.0 \%)$ & $34(7.4 \%)$ & $426(92.6 \%)$ & 0.039 \\
\hline White & $656(78.5 \%)$ & $26(4.0 \%)$ & $630(96.0 \%)$ & \\
\hline Black & $71(8.5 \%)$ & $5(7.0 \%)$ & $66(93.0 \%)$ & $0.215^{*}$ \\
\hline Hispanic & $54(6.5 \%)$ & $3(5.6 \%)$ & $51(94.4 \%)$ & $0.478^{*}$ \\
\hline Asian & $32(3.8 \%)^{\dagger}$ & $12(37.5 \%)$ & $20(62.5 \%)$ & $0.0001^{*}$ \\
\hline Native American & $8(1.0 \%)$ & $1(12.5 \%)$ & $7(87.5 \%)$ & $0.284^{*}$ \\
\hline Unknown & $10(1.2 \%)$ & $2(20.0 \%)$ & $8(80.0 \%)$ & $0.062^{*}$ \\
\hline All nonwhite & $175(20.9 \%)$ & $23(13.1 \%)$ & $152(86.9 \%)$ & $0.0001^{*}$ \\
\hline Mean age \pm SD & $54.9 \pm 18.0$ & $40.3 \pm 19.1$ & $55.8 \pm 17.5$ & 0.0001 \\
\hline Mean age $\left(\right.$ adjusted $\left.^{\ddagger}\right) \pm S D$ & $56.4 \pm 17.2$ & $48.1 \pm 17.9$ & $56.7 \pm 17.1$ & 0.008 \\
\hline
\end{tabular}

*Compared to white race.

tIncludes 9 of 23 Southeast Asians ( $P<0.0001$, compared to whites) and 3 of 9 other Asians $(P=0.005)$.

$\neq$ Outbreak-related subjects $(n=49)$ removed.

BuAg, Blastomyces urine antigen; SD, standard deviation.

for 3 cases (maximum increase of $0.56 \mathrm{ng} / \mathrm{ml}$ over index test value). Final serial titers were all lower than the initial test or were negative. A second BuAg was performed in 21 of $787(2.7 \%)$ negative tests; median time of repeat was 14 days (range: 1-510 days). One test was repeated twice; all repeat tests were negative.

Histoplasma urine antigen was co-performed with BuAg in $69.1 \%$ of all cases, and was positive in 25 of 578 (4.3\%); 16 of these 25 (64.0\%) were also BuAgpositive.

\section{Patient Presentation}

Of 100 patients who had $\mathrm{BuAg}$ testing and were examined for index illness details, 87 presented with pulmonary disease (including 1 patient each with skin or bone involvement). The 13 nonpulmonary presentations included skin $(n=5)$, bone $(n=2)$, central nervous system $(n=2)$, sinusitis $(n=1)$, sepsis $(n=1)$, fatigue/weight loss $(\mathrm{n}=1)$, and pretransplant screening $(n=1)$. Seven patients were ultimately diagnosed with blastomycosis (6 of which had positive BuAg); 7 had other systemic fungal disease, 26 had noninfectious lung disease, 22 had pneumonia, 5 had skin lesions, 6 had malignancies, 3 had mycobacteria, 11 had other specific diagnoses, and 1 had unknown etiology. Twelve individuals were tested based on symptoms and/or exposure, without definitive diagnosis, including 9 with cough/viral symptoms (5 of which had outbreak exposure), 2 with fever of unknown source, and 1 exhibiting fatigue and weight loss. None of these 12 patients were $\mathrm{BuAg}$-positive.

In the randomly selected cohort, 59 patients were hospitalized during the illness. Time intervals from onset of the index illness to the BuAg test and from BuAg to final diagnosis are presented in Table 2.

Among the 100 patients tested with BuAg who were examined in detail, 48 patients had at least one fungal culture during the index illness and 19 had histopathologic examination or cytology. Specific testing for Histoplasma was performed on 65 patients, and 24 were tested for Coccidioides, 18 for Cryptococcus, 30 for Aspergillus, 50 for mycobacteria and 15 for Pneumocystis jirovecii.

Among those with active pulmonary symptoms at the time of presentation $(n=70)$ and whose records included information regarding a particular symptom, a majority 
Table 2. Time, by Category, From Illness Onset to Test and From Test to Diagnosis

\begin{tabular}{lcc}
\hline Time category & $\begin{array}{c}\text { From onset } \\
\text { to BuAg test }\end{array}$ & $\begin{array}{c}\text { From BuAg } \\
\text { to diagnosis }\end{array}$ \\
\hline$<7$ days, $\mathrm{n}$ & 24 & 76 \\
$7-30$ days, $\mathrm{n}$ & 33 & 13 \\
1-3 months, $\mathrm{n}$ & 19 & 6 \\
$>3$ months, $\mathrm{n}$ & 8 & 2 \\
\hline Total $\mathrm{N}$ & 84 & -
\end{tabular}

BuAg, Blastomyces urine antigen.

had the following: dyspnea (44 of 50 [88\%]), cough (58 of 67 [87\%]), fatigue (32 of 40 [80\%]), myalgias/ muscle pain (12 of 20 [60\%]), night sweats (14 of 24 [58\%]), and fever (34 of 61 [56\%]). A minority had weight loss (42\%), chest discomfort (30\%), bone/joint pain $(24 \%)$, and hemoptysis $(20 \%)$.

\section{DISCUSSION}

$\mathrm{BuAg}$ appears to be commonly utilized in this large integrated health system with clinic locations spanning eastern Wisconsin. The ultimate diagnoses (pneumonia, noninfectious pulmonary processes, other systemic fungal disease, malignancies, mycobacterial disease) of the 100 randomly selected BuAg-tested patients for detailed analysis are consistent with the differential diagnosis of blastomycosis as presented in texts and reviews, ${ }^{1,6}$ and with the results of a survey of Wisconsin clinicians who were asked to list their top three diagnoses when presented blindly with various case vignettes of blastomycosis presentations. ${ }^{7}$ Similarly, for active pulmonary disease (while readily acknowledging the limitations of retrospective EMR review), mean age, gender distribution, and presenting symptomatology was quite similar to that recently reported from northern Wisconsin, except that dyspnea was significantly more prevalent in the present report. ${ }^{18}$ Thus, BuAg appears to be ordered in clinical settings that indeed would include blastomycosis in the differential diagnosis.

The calculated sensitivity of $\mathrm{BuAg}$ in this study, $85.7 \%$, may be compared with the reports of Durkin et al (92.9\%, calculated from 42 cases) ${ }^{11}$ Connolly et al, who used quantitative BuAg (89.9\%, 89 cases), ${ }^{12}$ and
Bariola et al, who used quantitative BuAg in newly diagnosed patients $(85.1 \%, 27$ cases $) .{ }^{15}$ It is apparently similar to Azar et al (exact figure not reported). ${ }^{13}$ Our figure is higher than that reported by Frost and Novicki $(76.3 \%, 59$ cases, mixture of qualitative and quantitative $\mathrm{BuAg}$ ), despite our study's similarly broad representation of patients from an endemic area of Wisconsin. ${ }^{14}$ Our study exclusively included quantitative $\mathrm{BuAg}$, and the proportion of isolated pulmonary cases was greater in their study (88\%) than ours (69\%); however, such cases had the highest BuAg sensitivity $(82.7 \%)$ in their study. ${ }^{14}$

Ignoring cross-reactivity with Histoplasma, our calculated specificity (97.9\%) was similar to that of Connolly et al (99.0\%). ${ }^{12}$ Our cross-reactivity (64\%) was lower than that found by others (up to $96 \%$ ), ${ }^{11,12,15}$ but still substantial. As previously suggested, further tests and relative values of the two positive assays can be considered to differentiate histoplasmosis from blastomycosis. ${ }^{12,15}$ Fortunately, initial treatment of these two mycoses is similar such that therapy may be started while awaiting specific confirmation. ${ }^{1,2,19}$

The poor sensitivity of antibody testing by the older $\mathrm{CF}$ and ID techniques is well known ${ }^{1-3}$ and was further confirmed by our study. In no instance did these tests contribute to the diagnosis of blastomycosis. The current charge for each of these tests is approximately $\$ 80$, which may be saved by not ordering them. Antibody testing for Blastomyces surface protein BAD-1 by enzyme immunoassay, in combination with BuAg, shows promise for sensitive and specific blastomycosis diagnosis, as the former has minimal cross-reactivity with Histoplasma. ${ }^{20}$

Based on recorded histories, 49 of $836 \mathrm{BuAg}$ tested subjects had exposure to the environs of the Little Wolf River during and shortly after the 2015 Waupaca County blastomycosis outbreak, ${ }^{17}$ with onethird testing positive for Blastomyces. BuAg testing appeared particularly useful in this setting. As of this writing, no summary of the complete outbreak has been published.

Our study revealed that Asians were significantly overrepresented regarding the proportion of those tested with BuAg who were positive (37.5\%). Recent 
studies have suggested differing susceptibility to blastomycosis among different human genetic and ethnic groups. ${ }^{12,21}$ Roy et al found significantly higher blastomycosis incidence rates among Asians in sporadic and outbreak cases. ${ }^{22}$ The genesis of these findings is not clear, but the overrepresentation of Asians in outbreak or hyperendemic areas may be due to genetic predisposition and/or socioeconomic reasons.

Finally, BuAg was the only positive test in a significant portion of apparent blastomycosis cases. Such cases may not be reported, as they do not meet the Wisconsin case definition for blastomycosis. ${ }^{23}$ Thus, the true incidence of blastomycosis may be underestimated.

\section{Limitations}

The limitations of our study include all of those inherent in retrospective EMR reviews. Our study was limited to a single health system in a moderately high endemic area. ${ }^{24}$ The calculations of test characteristics were based on 33 patients (not unlike other studies). ${ }^{11,15}$ We were unable to provide a comparison group of patients presenting with a similar clinical presentation who were not tested with BuAg. Our strengths included a moderately large, comprehensive study of outpatients and inpatients tested with $\mathrm{BuAg}$ (rather than just those who tested positive or who were diagnosed with blastomycosis by some means).

\section{CONCLUSIONS}

Blastomyces urine antigen testing appears to be commonly performed in this region for work-up of broad differential diagnoses that appropriately include blastomycosis or for symptomatic patients with known exposure to the fungus. It may be particularly useful in outbreak settings. Fungal culture and $\mathrm{BuAg}$ testing (perhaps with the future addition of antibody testing for Blastomyces surface protein BAD-1) are the preferred tests for Blastomyces in symptomatic patients from an endemic area. Not adding highly insensitive $\mathrm{CF}$ and ID tests to $\mathrm{BuAg}$ testing for blastomycosis would save money without losing sensitivity.

\section{Patient-Friendly Recap}

- There are a number of diagnostic tests used to confirm suspected blastomycosis, a fungal infection of the lungs.

- One such test, referred to as BuAg, uses the patient's urine to look for byproducts of the fungus Blastomyces.

- The author found that BuAg is commonly ordered by local physicians and yields test results reasonably comparable to the more time-consuming culture method.

- Also shown was that a pair of alternative antibody tests did not add true diagnostic value, making their use inadvisable.

\section{Acknowledgments}

The author thanks Julie Prabucki, MT, for providing laboratory data, Chris Blumberg, MS, for clinical data, and Jessica J. F. Kram, $\mathrm{MPH}$, for logistic and regulatory assistance.

\section{Conflicts of Interest}

None.

\section{References}

1. Bradsher RW Jr. Blastomycosis. In: Bennett JE, Dolin R, Blaser MJ (eds). Mandell, Douglas, and Bennett's Principles and Practice of Infectious Diseases, Eighth Edition. Philadelphia, PA: Elsevier Saunders, 2015, pp. 2963-73.

2. Smith JA, Gauthier G. New developments in blastomycosis. Semin Respir Crit Care Med. 2015;36:715-28. CrossRef

3. Smith JA, Kauffman CA. Blastomycosis. Proc Am Thorac Soc. 2010;7:173-80. CrossRef

4. Brown EM, McTaggart LR, Zhang SX, et al. Phylogenetic analysis reveals a cryptic species Blastomyces gilchristii, sp. nov. within the human pathogenic fungus Blastomyces dermatitidis. PLoS One. 2013;8(3):e59237. CrossRef

5. Seitz AE, Adjemian J, Steiner CA, Prevots DR. Spatial epidemiology of blastomycosis hospitalizations: detecting clusters and identifying environmental risk factors. Med Mycol. 2015;53:447-54. CrossRef

6. Bariola JR, Vyas KS. Pulmonary blastomycosis. Semin Respir Crit Care Med. 2011;32:745-53. CrossRef

7. Baumgardner DJ, Temte JL, Gutowski E, et al. The differential diagnosis of pulmonary blastomycosis using case vignettes: a Wisconsin Network for Health Research (WiNHR) study. WMJ. 2011;110:68-73.

8. Martynowicz MA, Prakash UB. Pulmonary blastomycosis: an appraisal of diagnostic techniques. Chest. 2002;121;768-73. CrossRef

9. Patel AJ, Gattuso P, Reddy VB. Diagnosis of blastomycosis in surgical pathology and cytopathology: correlation with microbiologic culture. Am J Surg Pathol. 2010;34:256-61. CrossRef 
10. Lemos LB, Guo M, Baliga M. Blastomycosis: organ involvement and etiologic diagnosis. A review of 123 patients from Mississippi. Ann Diagn Pathol. 2000;4:391-406. CrossRef

11. Durkin M, Witt J, Lemonte A, Wheat B, Connolly P. Antigen assay with the potential to aid in diagnosis of blastomycosis. J Clin Microbiol. 2004;42:4873-5. CrossRef

12. Connolly P, Hage CA, Bariola JR, et al. Blastomyces dermatitidis antigen detection by quantitative enzyme immunoassay. Clin Vaccine Immunol. 2012;19:53-6. CrossRef

13. Azar MM, Assi R, Relich RF, et al. Blastomycosis in Indiana: clinical and epidemiologic patterns of disease gleaned from a multicenter retrospective study. Chest. 2015;148:1276-84. CrossRef

14. Frost HM, Novicki TJ. Blastomyces antigen detection for diagnosis and management of blastomycosis. J Clin Micrbiol. 2015;53:3660-2. CrossRef

15. Bariola JR, Hage CA, Durkin M, et al. Detection of Blastomyces dermatitidis antigen in patients with newly diagnosed blastomycosis. Diagn Microbiol Infect Dis. 2011;69:187-91. CrossRef

16. Huber ME, Baumgardner DJ, Kram JJ, Lemke MA. Geodemographic features of human blastomycosis in eastern Wisconsin. J Patient Cent Res Rev. 2016;3:90-8. CrossRef

17. Wisconsin Department of Health Services. Updated information: blastomycosis associated with the Little Wolf River in Waupaca County. News release (August 14, 2015).
18. Baumgardner DJ, Bernhard KA, Egan G. Pulmonary blastomycosis in Vilas County, Wisconsin: weather, exposures and symptoms. J Patient Cent Res Rev. 2015;2:25-33. CrossRef

19. Deepe GS Jr. Histoplasma capsulatum (histoplasmosis). In: Bennett JE, Dolin R, Blaser MJ (eds). Mandell, Douglas, and Bennett's Principles and Practice of Infectious Diseases, Eighth Edition. Philadelphia, PA: Elsevier Saunders, 2015, pp. 2949-62.

20. Richer SM, Smedema ML, Durkin MM, et al. Development of a highly sensitive and specific blastomycosis antibody enzyme immunoassay using Blastomyces dermatitidis surface protein BAD-1. Clin Vaccine Immunol. 2014;21:143-6. CrossRef

21. Meece JK, Anderson JL, Gruszka S, Sloss BL, Sullivan B, Reed KD. Variation in clinical phenotype of human infection among genetic groups of Blastomyces dermatitidis. J Infect Dis. 2013;207:814-22. CrossRef

22. Roy M, Benedict K, Deak E, et al. A large community outbreak of blastomycosis in Wisconsin with geographic and ethnic clustering. Clin Infect Dis. 2013;57:655-62. CrossRef

23. Wisconsin Department of Health Services. Blastomycosis. https://www.dhs.wisconsin.gov/disease/epi-blastomycosis. pdf. Accessed September 20, 2017.

24. Reed KD, Meece JK, Archer JR, Peterson AT. Ecologic niche modeling of Blastomyces dermatitidis in Wisconsin. PLoS One. 2008;3(4):e2034. CrossRef

(C) 2018 Aurora Health Care, Inc. 